\title{
Teachers use of fear appeals and timing reminders prior to high-stakes examinations: pressure from above, below, and within
}

\author{
David W. Putwain ${ }^{1}$ (D) Nathaniel P. von der Embse ${ }^{2}$
}

Received: 19 December 2017 / Accepted: 28 March 2018 / Published online: 29 May 2018 (C) The Author(s) 2018

\begin{abstract}
Teachers often communicate to students the consequences of success and failure (fear appeals) and the timing (timing reminders) of forthcoming examinations. Prior research has examined how fear appeals and teaching reminders are evaluated by students and how they relate to educational outcomes such as engagement. Few studies have addressed the use of these behaviours from a teacher's perspective. We examined teacher use of consequence and timing reminders, used prior to examinations, and its relation to perceived accountability pressure, teacher self-efficacy, perceived importance of tested outcomes, and the belief that students would interpret such messages as threatening. Data were collected from 854 English primary and secondary school teachers. Results showed that fear appeals and timing reminders were used more frequently when teachers believed that tested outcomes were important, when they had lower self-efficacy to engage students, and when they believed that students would interpret messages as threatening. Timing reminders, but not fear appeals, were used more frequently when perceived accountability pressure was greater. These findings help to understand why teachers are using such behaviours. In this study it was pressures from above, below, and within.
\end{abstract}

Keywords Fear appeals $\cdot$ Timing reminders - Accountability $\cdot$ Teacher selfefficacy $\cdot$ Importance of tested outcome $\cdot$ Threat appraisal $\cdot$ High-stakes testing

David W. Putwain

D.W.Putwain@1jmu.ac.uk

1 School of Education, Liverpool John Moores University, IM Marsh Campus, Mossley Hill Rd, Liverpool L17 6DB, UK

2 College of Education, University of South Florida, Tampa, FL, USA 


\section{Introduction}

In this study we examine two types of messages given to students prior to examinations by their teachers: Fear appeals and timing reminders. Fear appeals are persuasive messages that describe how a course of action (e.g., not making an effort) can lead to negative consequences (i.e., examination failure) and how an alternate course of action (e.g., high effort) can avoid those negative consequences. Timing reminders are messages that highlight the date and timing of a forthcoming examination, along with the remaining time for preparatory opportunities before that test or examination. Several studies have examined how students interpret such messages and how they might relate to subsequent educational motivation, engagement, and achievement (e.g., Putwain and Remedios 2014; Putwain et al. 2017a). Few studies to date have examined the reasons why teachers might use such messages (e.g., Putwain and Roberts 2012; Putwain et al. 2017a). Consequently, the current understanding of the reasons for using such behaviours is limited. In the present study, we address this concern and examine if teachers use of fear appeals and timing reminders are related to perceived accountability pressure, teacher self-efficacy, perceived test importance, and whether teachers believed students would interpret messages as threatening.

\subsection{Teacher use of fear appeals and timing reminders}

Prior to high-stakes examinations, teachers and school staff may communicate a multitude of information to students and their parents. Some of this is purely administrative referring to details, such as the time, venue, and length of a particular examination. However, other information is communicated that concerns the importance, value, and consequences of those examinations, along with the importance of preparation. These include how failure could influence one's sense of self-worth and damage future life chances, the timing of their forthcoming examinations, and the time left available to prepare (Putwain and Roberts 2009; Putwain et al. 2012). Such messages are conceptualised to have a motivational function. That is, to encourage students to work hard in preparing for their examinations, persist with difficulties, and engage with their studies (Putwain and Roberts 2012).

When used prior to high-stakes examinations, fear appeals are defined as persuasive messages that highlight how failure can have negative consequences for future educational attainment (e.g., progression to a subsequent stage of education or entry to a particular college, university or training program), occupational aspirations (e.g., where access to a competitive labour market requires particular grades or a profile of grades), one's sense of self-worth, or social concerns (e.g., peer competition, parental expectations). Fear appeals are conceptualized as a communicated high-value, high-cost, message (Putwain and Symes 2014; Putwain et al. 2017c). That is, two elements are communicated in the message. These are the value or importance of the examination for the student concerned (high value), and the consequences that would likely result from failure (high cost). 
Early measures of fear appeals used prior to high-stakes examinations (e.g., Putwain and Roberts 2009) included messages regarding the timing of those examinations. Later measures (e.g., Putwain et al. 2017c) have moved away from this approach. As timing reminders can be used without any reference to value or cost, they can be conceptualised as a distinct message altogether; a regulative behavioural prompt. Timing reminders are defined as messages concerning the timing of a forthcoming examination which highlight the preparation time left available. From a self-regulatory perspective (e.g., (Cleary and Zimmerman 2012; Zimmerman 2000; Kitsantas and Cleary 2016), timing reminders serve to prompt students about the necessary activities required to achieve goals (i.e., what needs to be achieved in the time available). If students have not yet begun exam preparation, or are doing so with little effort, timing reminders could emphasize the need to set (or re-set) goals and plan the steps required to achieve those goals (for examples of regulatory prompts to scaffold learning see Boekaerts and Corno 2005; Perry et al. 2008; Peters and Kitsantas 2010).

\subsection{Student appraisal of fear appeals and timing reminders}

In their appraisal model, Putwain and Symes $(2014,2016)$ propose that links to subsequent educational outcomes depend on how examination messages are understood and evaluated by the students. If the student values the outcome highlighted in the message (e.g., examination success) and believe they are capable of achieving that outcome, they interpret the message as a challenge, experience positive emotions (e.g., hope and optimism), and respond with positive behavioural intentions (e.g., work hard and concentrate in lessons). If the student values the outcome highlighted in the message (e.g., examination success) but does not believe they are capable of achieving that outcome, they interpret the message as a threat, experience negative emotions (e.g., hopelessness and anxiety), and respond with avoidance behaviours (e.g., strategic withdrawal of effort and procrastination). Empirical studies have provided support for both the appraisal model (e.g., Putwain et al. 2016a; Symes and Putwain 2016) and the links to educational outcomes in samples of primary school (Putwain and Best 2011, 2012), secondary school (e.g., Putwain and Symes 2011a, b; Putwain et al. 2017b), and undergraduate students (e.g., von der Embse et al. 2015).

\subsection{Reasons for teachers' use of fear appeals}

A notable absence from this body of work has been the reasons or antecedents for why teachers might use fear appeals and timing reminders. Only three studies to date have addressed this question. Putwain and Roberts (2012) examined if the use of fear appeals prior to a high-stakes examination was related to teachers' beliefs about students in a sample of secondary school teachers of different subjects. Teachers reported more fear appeal use if they believed that students would find them motivating (indicative of a challenge appraisal) and using them less if they believed students would find them worrisome or anxiety provoking (indicative of a threat 
appraisal). The use of fear appeals did not differ according to the academic success of the school or the number of years for which a teacher had been in service. Putwain et al. (2017b), examined if teachers use of fear appeals was related to their perception of students as being less engaged in their classroom work in a sample secondary school mathematics teachers. Results supported predictions and showed that teacher-reported behavioural engagement predicted greater use of teacher-reported fear appeals. Finally, in a large-scale survey of secondary school teachers von der Embse et al. (2017) found that greater use of accountability practices (e.g., using student test scores to inform decisions about pay and teacher evaluation) and a high importance afforded to tested outcomes by teachers were associated with greater use of fear appeals and timing reminders.

These initial studies into the reasons for which teachers use fear appeals and timing reminders suggest three sources of antecedents: Pressure from above, pressure from below, and pressure from within (see Pelletier et al. 2002; Reeve 2009). Pressures from above refer to demands or requirements from external sources with organisational authority (e.g., managers, school leaders, or school inspectors) and include imposed curriculum reform, making teachers accountable for student performance, and imposing sanctions and rewards on teachers for student performance. Pressures from below refer to the behaviours of students, real or perceived, for which the teacher is responsible (e.g., student engagement, motivation, affect, and achievement). Pressure from within refers to teachers own values, beliefs, and self-perceptions (e.g., teacher self-efficacy, importance of tested outcomes) that influence their behaviour. Using these three influences as a guide, we include in the present study one pressure from above (perceived accountability pressure), one pressure from below (whether students are judged as likely to interpret fear appeals and timing reminders as a threat), and two pressures from within (teacher self-efficacy and the perceived importance of the tested outcome).

\subsection{Perceived accountability pressures}

Accountability systems that use student examination scores as means to judge teacher or whole school effectiveness have become widespread in many educational systems (OECD 2013). In England, where the present study was located, student progression and scores on tested outcomes (e.g., National Curriculum Tests: NCTs, General Certificate of Secondary Education: GCSEs) are used by the school inspectorate to inform decisions over teacher pay and promotion, and to rank schools within a particular locality on the basis of student performance (Department of Education 2016; Perryman 2006; Perryman et al. 2011; Roberts and Abreu 2016). When teachers are pressured by accountability systems that use incentives and sanctions based on students examination results, their behaviours are altered in ways to become more controlling (e.g. Pelletier et al. 2002; Reeve 2009). Teachers limit the curriculum and student learning on tested outcomes (e.g., Banks and Smythe 2015; Hall et al. 2004). Under such circumstances, we would also anticipate teachers to use fear appeals and timing reminders more frequently as part of a general strategy to ensure student motivation and engagement. Only one known study to date 
demonstrated, within a large sample from the United States, that teachers were more likely to use fear appeals and timing reminders when their local school districts used test performance to inform judgments about annual job evaluations and salary increments (von der Embse et al. 2017).

\subsection{Interpretation of fear appeals and timing reminders as threatening}

In the appraisal model outlined above, fear appeals and timing reminders can be interpreted and understood in different ways by students (Putwain and Symes 2014, 2016). They can be appraised as a challenge, leading to greater motivation and engagement, or as a threat, leading to lower motivation and engagement. If fear appeals and timing reminders are used as part of a general strategy to promote motivation and engagement then it would be expected that teachers would use fear appeals and timing reminders less frequently if students showed a threat appraisal (i.e., worry and anxiety) that indicated lower motivation and engagement. The abovementioned study by Putwain and Roberts (2012) supported this theorising; a negative correlation was reported between teacher use of fear appeals and their belief that students would respond to fear appeals with worry and anxiety.

\subsection{Teacher self-efficacy}

Teacher self-efficacy refers to beliefs that one is capable of planning, organizing, and conducting those activities required to achieve educational goals (Skaalvik and Skaalvik 2007). To capture beliefs held by teachers regarding different areas of functioning and undertaken within daily activities, a multidimensional conceptualization of teacher self-efficacy is required (Klassen et al. 2011). Tschannen-Moran and Woolkfolk Hoy (2001) proposed three domains of teacher self-efficacy: implementing instructional strategies, managing student's behaviours, and engaging students in learning. Higher self-efficacy positively correlates with job satisfaction (Klassen and Chiu 2010), higher occupational commitment and lower intention to leave the profession (Klassen and Chiu 2011), and teachers with higher self-efficacy are judged as being more effective teachers in terms of student performance and observations by independent evaluators (Klassen and Tze 2014).

Research has yet to examine the links between teacher self-efficacy and the use of fear appeals and timing reminders. Given that fear appeals and timing reminders are conceptualized as strategies for increasing motivation and engagement, the most germane of the three domains of teacher self-efficacy would be engaging students in learning. Greater teacher self-efficacy is associated with higher student motivation (Schiefele and Schaffner 2015) and a belief that it is possible to engage students who are initially unmotivated (Tschannen-Moran et al. 1998). Furthermore, teachers are more likely to use frequent fear appeals when they perceive students to be lacking engagement (Putwain et al. 2017b). On the basis of studies linking teacher self-efficacy with the ability to engage unmotivated students (Putwain et al. 2017b; Schiefele and Schaffner 2015; Tschannen-Moran et al. 1998), it would be plausible to expect that in classes with unengaged students, teachers might hold lower 
self-efficacy beliefs in their ability to engage such students in learning (e.g., planning interesting lessons, or engaging activities). Consequently, teachers may resort to more controlling tactics, such as fear appeals and test reminders, in an attempt to motivate and engage students. Research is necessary to further elucidate these essential predictors in the use of consequence and test reminders.

\subsection{Perceived importance of test outcomes}

The importance afforded to different aspects of a teacher's professional role can provide insight into the value systems of teachers, including professional ethics, personal beliefs, and character values (Brady 2011), and provide an account of the motivations behind particular behaviours and instructional practices (Metzger and $\mathrm{Wu}$ 2008). In this study, we examined the importance of student achievement in forthcoming student examinations (NCTs or GCSEs) for a teacher's sense of professional identity. Teacher professional identity has been defined as the ongoing dynamic pursuit of development and learning in accordance with one's goals (Beauchamp and Thomas 2009). It comprises of an affinity for a particular task or role, shared with and arising from a community of shared practice with colleagues (Gee 2000). Based on this conceptualisation, we would anticipate that teachers who place high importance on student achievement for their professional identity would engage in practices with the potential to maximise students' achievement of tested outcomes, and such strategies would potentially include fear appeals and timing reminders. One study to date, conducted on a large sample of secondary school teachers from the United States, has investigated this relationship that teachers who placed high importance on tested outcomes used more fear appeals and timing reminders more frequently (von der Embse et al. 2017).

\subsection{Aims of the present study}

At present, there are few studies that have addressed reasons or antecedents for teachers' use of fear appeals and timing reminders. Furthermore, studies conducted to date have tended to examine antecedents of such behaviours in isolation. In the present study, we address this concern by examining the role of four potential antecedents (perceived accountability pressure, teacher self-efficacy, perceived test importance, and whether teachers believed students would interpret messages as threatening) within a threefold integrative framework (pressure from above, below, and within) to build a comprehensive model or understanding of teacher use of fear appeals and timing reminders. Based on the theoretical propositions outlined above, we anticipate that teachers will report using more fear appeals and timing reminders when they perceive high accountability pressure $(H I)$, have lower teacher selfefficacy, particularly in student engagement $(\mathrm{H} 2)$, place high importance on tested outcomes $(H 3)$, and believe that students would experience low threat in response (H4). The a priori model is shown in Fig. 1. 


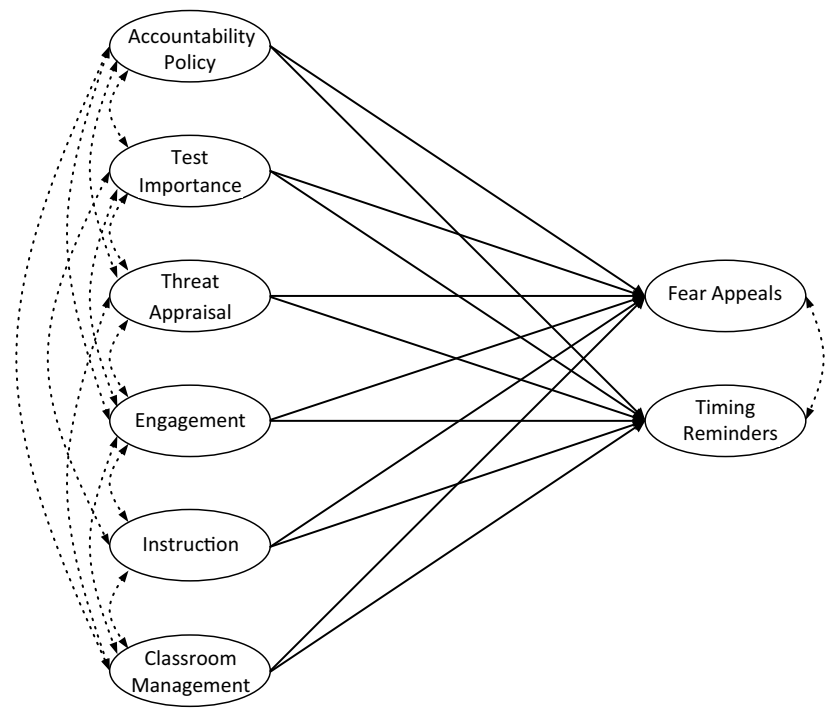

Fig. 1 Hypothesised model to examine relations from perceived accountability pressure, teacher selfefficacy, perceived test importance, and threat appraisal, to fear appeals and timing reminders. Solid lines represent structural paths and dashed lines represent correlations

\section{Method}

\subsection{Participants}

The participants were 839 school teachers $($ male $=214$, female $=624$, transgender $=1$ ). The majority of teachers were between 30 and 39 years of age $(20-29$ years $=168,30-39$ years $=240,40-49$ years $=219,50-59$ years $=175,>60$ years $=35$, missing $=2)$ and had been teaching for more than 15 years $(<1$ year $=39$, $1-5$ years $=168,5-10$ years $=167,11-15$ years $=151,>15$ years $=312$, missing $=2)$. The ethnic heritage of participants was predominantly white Caucasian $(n=803)$ with smaller numbers from Asian $(n=15)$, Black $(n=6)$, other $(n=9)$ and mixed heritage $(n=3)$. The majority of participants worked in primary schools, which in the English education system covers ages 5-11 $(n=459)$, followed by secondary schools which covers ages $11-19(\mathrm{n}=354)$. A small number of participants $(n=23)$ worked in other settings (e.g., pre-school or residential education; missing data $=3)$. In the main these were state funded schools $(n=817$, missing $n=5)$. Most teachers $(n=600$, missing $n=3)$ taught a subject that was tested in NCTs (for primary school teachers) or GCSEs (for secondary school teachers). 


\subsection{Measures}

\subsubsection{Perceived accountability pressure}

Perceived accountability pressure was measured via three items designed for the purpose of this study. Participants reported whether their school used student test or examination performance data (NCTs or GCSEs) for teacher performance evaluations ('In my school, it is policy to use student performance on GCSE or National Curriculum Tests for teacher evaluations and/or performance review'), decisions over whether to grant newly qualified teachers as having fully qualified teacher status ('In my school, it is policy to use student performance on GCSE or National Curriculum Tests for decisions whether to pass the NQT year'), ${ }^{1}$ and performancerelated pay ('In my school, it is policy to use student performance on GCSE or National Curriculum Tests for performance-related pay and/or promotion'). Participants responded on a binomial category of 'yes' (coded as 1) or 'no' (coded as $0)$. Responses were summed to provide a four-point scale of $0-3$, where 0 would represent a school where accountability policies were not perceived to be strongly tied to student test/examination performance and 3 would represent a school where accountability policies were perceived to be strongly tied to student test/examination performance. Internal reliability was moderate (McDonald's $\omega=.65$ ).

\subsubsection{Teacher self-efficacy}

Teacher self-efficacy was measured using the short version of the Teachers' Selfefficacy Scale (TSES; Tschannen-Moran and Woolkfolk Hoy 2001) which contains three 4-item scales: efficacy in instructional strategies, student engagement, and classroom management. Participants responded to items (e.g., 'How much can you do to motivate students who show low interest in school work?' for instructional strategies, 'To what extent can you craft stimulating lessons for your students?' for student engagement, and 'How much can you do to control disruptive behaviour in the classroom?' for classroom management) on a five-point scale $(1=$ Nothing, $3=$ Some influence, and 5=A great deal). The structural and predictive validity, cross-cultural invariance, and internal reliability, of data collected using the TSES has been evidenced in a several studies (e.g., Klassen et al. 2009; Klassen and Chiu 2010; Tschannen-Moran and Woolkfolk Hoy 2007). The internal reliability coefficients in the present study were good (McDonald's $\omega$ instructional strategies $=.83$, student engagement $=.76$, and classroom management $=.87$ ).

\footnotetext{
${ }^{1}$ For those who may not be familiar with the English education system, NQT refers to "newly qualified teacher' who has completed an accredited in-school or university training course (typically four year undergraduate or one year postgraduate). NQTs must satisfactorily complete a further year of supervised in-school practice to gain a permanent (tenured) contract of employment.
} 


\subsubsection{Perceived importance value of test outcome}

Perceived importance of test outcome was measured using six items adapted for the English context from the scale used by von der Embse et al. (2017). Participants responded to items (e.g., 'Having my students do well on the GCSEs/NCTs is important for me as a teacher') on a five-point scale ( $1=$ Not at all, $3=$ Somewhat, and $5=$ Very much). The internal reliability coefficient in the present study was good (McDonald's $\omega=.83$ ).

\subsubsection{Teacher use of fear appeals and timing reminders and threat appraisal by students}

These were measured using nine items from the Teachers Use of Fear Appeals Questionnaire (Putwain and Roberts 2009). Original items in this measure were student reported and referred specifically to GCSEs. The items used in the present study referred to both GCSEs and NCTs, used stems appropriate for teacher report (e.g., 'I remind my students...' rather than 'How often does your teacher...'), and omitted specific references to GCSE outcomes (e.g., going to college) in favour of general outcomes (e.g., importance for the future). Exemplar items include 'I remind my students of the importance of the GCSEs/NCTs to their future' for fear appeals (three items), 'I remind my students of the days or weeks until the GCSEs/NCTs' (three items) for timing reminders, and 'My students are worried if I tell them that the GCSEs/NCTs are important to their future' (three items) for threat appraisal. Participants responded on a five-point scale $(1=$ Never, $3=$ Sometimes, and $5=$ Almost always). The internal reliability coefficients in the present study were good (McDonald's $\omega$ fear appeals $=.84$, timing reminders $=.90$, and threat appraisal $=.78$ ).

\subsection{Procedure}

Following approval from the Institutional Ethics Committee, the survey was hosted on an online platform. Invitations to participate in the study, addressed to the school Head or Principal, were sent via email to the administrative departments at partnership schools associated with the first author's institution. It was not possible to gauge how many invitation emails were filtered out by either host servers (that identified the email as 'spam'), administrators (who chose not to forward the email to the School Head or Principal), or by the School Head or Principal (who chose not to forward the survey link to staff). Although the online survey was anonymous, the responses of several demographics and school characteristics, when combined, could have lead to the impression that it was possible to identify particular individuals from their responses. To assuage this concern and ensure absolute anonymity the section of the survey containing questions pertaining to demographics and school characteristics was partitioned from the section of the survey containing questions asking about the substantive constructs, hosted on a separate URL and stored to a separate database. The initial link that participants received in the invitation email 
Table 1 Descriptive statistics for perceived accountability pressure, teacher self-efficacy, perceived importance of tests, fear appeals, timing reminders, and threat appraisal

\begin{tabular}{lllllll}
\hline & Range & Mean & SD & Skewness & Kurtosis & Factor loadings \\
\hline Perceived accountability pressure & $0-3$ & 0.48 & 0.32 & -0.23 & -1.02 & $.53-.99$ \\
$\begin{array}{l}\text { Teacher self-efficacy: instructional strate- } \\
\quad 1-5\end{array}$ & 4.18 & 0.56 & -0.42 & -0.07 & $.60-.75$ \\
$\quad$ gies & & & & & & \\
$\quad \begin{array}{l}\text { Teacher self-efficacy: student engagement } \\
\text { Teacher self-efficacy: classroom manage- }\end{array}$ & $1-5$ & 3.80 & 0.69 & -0.10 & -0.64 & $.52-.85$ \\
$\quad 1-5$ & 4.22 & 0.62 & -0.53 & -0.25 & $.76-.86$ \\
$\quad$ ment & & & & & & \\
Perceived importance of tested outcomes & $1-5$ & 3.88 & 0.86 & 0.76 & 0.14 & $.41-.95$ \\
Fear appeals & $1-5$ & 3.14 & 1.03 & -0.20 & -0.61 & $.64-.89$ \\
$\quad$ Timing reminders & $1-5$ & 3.25 & 1.09 & -0.28 & -0.61 & $.78-.86$ \\
Threat appraisal & $1-5$ & 3.24 & 0.92 & -0.39 & -0.23 & $.69-.83$ \\
\hline
\end{tabular}

accessed survey questions regarding demographics and school characteristics. At the end of this section of the survey participants received a further link to access questions pertaining to the substantive constructs. As a consequence, it was possible to characterize the sample, but was not possible to include any demographics or school characteristics in the subsequent analyses of substantive constructs.

\section{Results}

\subsection{Descriptive statistics and latent bivariate correlations}

Descriptive are reported in Table 1. All variables were normally distributed (skewness and kurtosis \pm 1 ) with the exception of perceived accountability pressures that showed a slight negative skew (-1.02). Factor loadings, from the confirmatory factor analysis described below) were all $\operatorname{good}(\lambda>.4)$. Latent bivariate correlations were estimated by conducting a confirmatory factor analysis of a measurement model using the maximum-likelihood estimator in Mplus 7.4 (Muthén and Muthén 2012). The measurement model consisted of perceived accountability pressure (3 items), teacher self-efficacy (12 items), perceived importance of tested outcomes (6 items), fear appeals, timing reminders, and threat appraisal (9 items). Missing data $(0.7 \%)$ was imputed using the full-information-maximum-likelihood procedure in Mplus (see Graham 2012).

Model fit was judged using the root mean square error of approximation (RMSEA), standardized root mean square residual (SRMR), comparative fit index (CFI), and the Tucker-Lewis index (TLI). RMSEA and SRMR values of $\leq .06$, and $\leq .08$, respectively, and CFI and TLI values of $\geq .95$ are indicative of a good fitting model (e.g., Hu and Bentler 1999). These values, however, should not be treated as strict cut-off scores, especially when using naturalistic data (e.g., Heene et al. 2011; Lance et al. 2006). This model showed a largely good fit to the data, $\chi^{2}(374)=790.16, \mathrm{RMSEA}=.047, \mathrm{SRMR}=.043, \mathrm{CFI}=.952$, and $\mathrm{TLI}=.944$, and so 
we proceed to examined correlation coefficients (reported in Table 2). Fear appeals and timing reminders were positively related to perceived accountability pressure, the perceived importance of tested outcomes, and threat appraisal, and negatively related to teacher self-efficacy.

\subsection{Structural equation modelling}

A structural equation model (SEM) was examined where perceived accountability pressure, teacher self-efficacy, perceived importance of tested outcomes, and threat appraisal, were treated as simultaneous predictors of fear appeals and timing reminders. Predictors (perceived accountability pressure, teacher self-efficacy, perceived importance of tested outcomes, and threat appraisal) and outcomes (fear appeals and timing reminders) were allowed to correlate freely. The SEM was analyzed in Mplus 7.4 (Muthén and Muthén 2012) using the maximum-likelihood estimator and assessed using the same criteria as the measurement model. The SEM showed a largely good fit to the data, RMSEA $=.048, \mathrm{SRMR}=.043, \mathrm{CFI}=.950$, and $\mathrm{TLI}=.942$, and so we proceed to examined standardised beta coefficients. Standardised regression coefficients can be interpreted as $\beta<.10$ as small, $\beta=.10-.25$ as moderate, and $\beta>.25$ as large (Keith 2006).

Teacher use of fear appeals was predicted by threat appraisal $(\beta=.463, p<.001)$, teacher self-efficacy for student engagement $(\beta=-.168, p=.03)$, and the perceived importance of the tested outcome $(\beta=.446, p<.001)$, but not accountability pressure $(\beta=.07, p=.13)$, teacher self-efficacy for classroom instruction $(\beta=.036, p=.70)$, or teacher self-efficacy for classroom management $(\beta=-.001, p=.94)$. Teacher use of timing reminders was predicted by accountability pressure $(\beta=.11, p=.02)$, threat appraisal $(\beta=.554, p<.001)$, teacher self-efficacy for student engagement $(\beta=-.219, p=.006)$, and the perceived importance of the tested outcome $(\beta=.268$, $p<.001)$, but not teacher self-efficacy for classroom instruction $(\beta=.116, p=.25)$, or teacher self-efficacy for classroom management $(\beta=-.021, p=.80)$. The SEM is shown in Fig. 2.

\section{Discussion}

The aim of this study was to examine how pressure from above (perceived school accountability pressure), pressure from within (teacher self-efficacy and importance of tested outcome), and pressure from below (belief that students would appraise messages as a threat), related to two teacher behaviours used prior to high-stakes examinations: Fear appeals and timing reminders. Fear appeals, where the teacher communicated to students the consequences of failure, were used more frequently when teachers believed students would interpret such messages as worrisome, when the tested outcome was judged as important, and when teachers reported low self-efficacy in their ability to engage students in learning. Timing reminders, where the teacher communicated to students the timing of the forthcoming examinations, and/or the time left for students to prepare, were used 


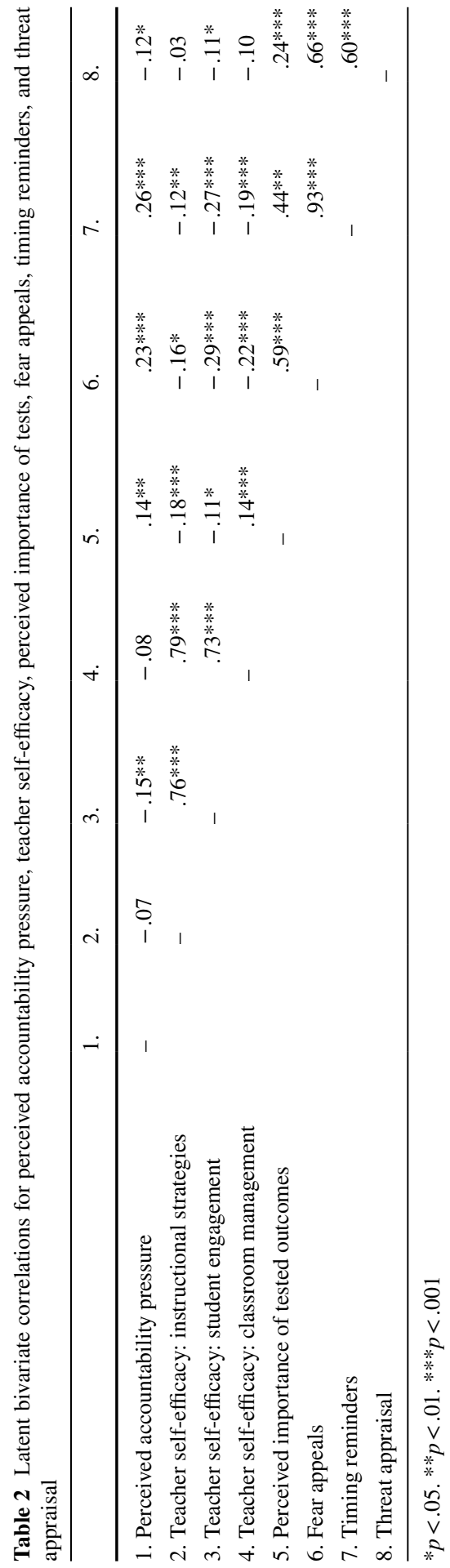




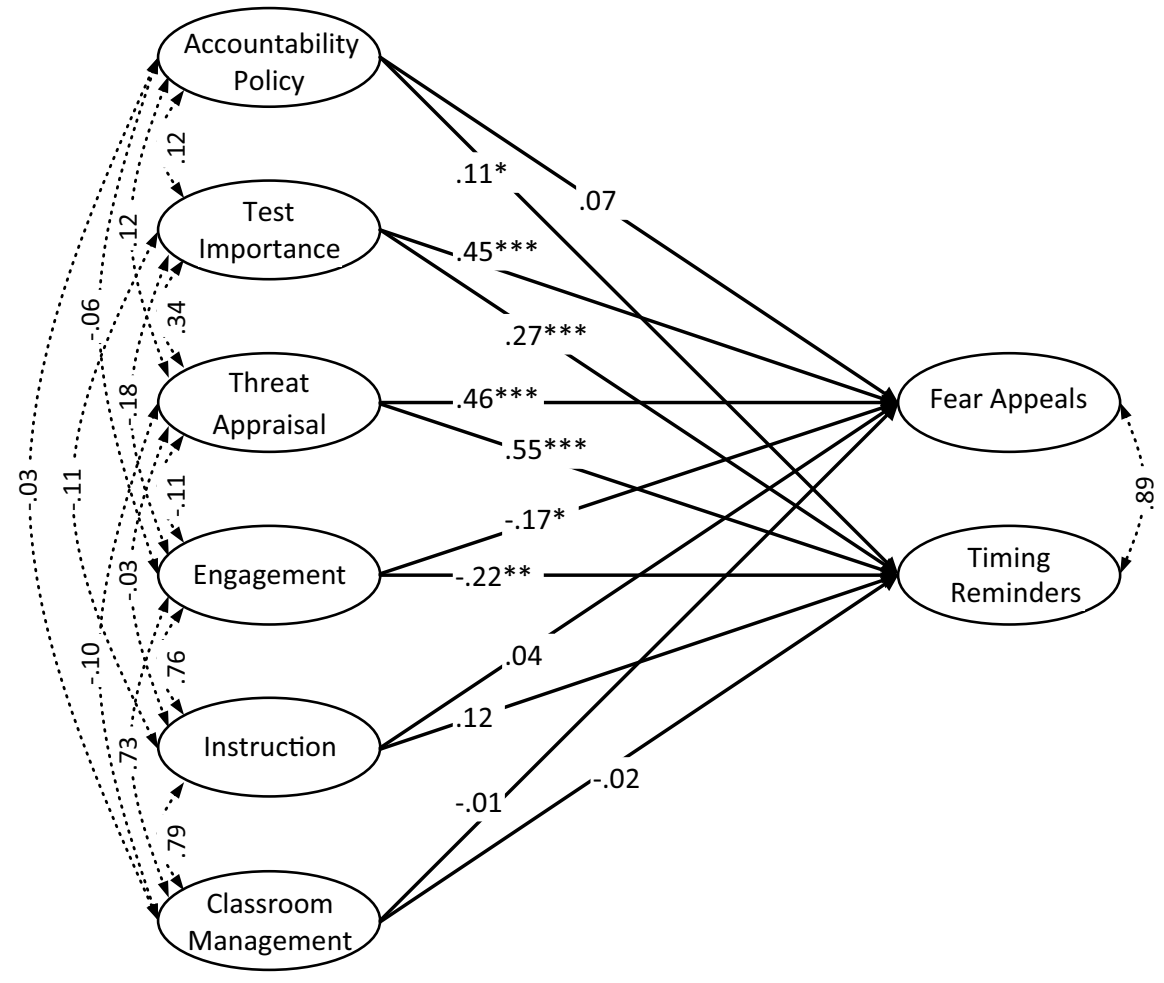

Fig. 2 SEM to show relations from perceived accountability pressure, teacher self-efficacy, perceived test importance, and threat appraisal, to fear appeals and timing reminders. Solid lines represent structural paths and dashed lines represent correlations

more frequently when teachers perceived greater accountability pressures, when teachers believed students would interpret such messages as worrisome, when the tested outcome was judged as important, and when teachers reported low selfefficacy in their ability to engage students in learning.

In England, where the data were collected, accountability policies can be enacted by schools in different ways. Some schools may place a greater emphasis on student test and examination outcomes for staff evaluation and appraisal, promotion, and performance-related pay. Other schools may place a lesser emphasis. We hypothesised that when teachers perceived greater accountability pressures, they would report using fear appeals and timing reminders more frequently. The data partially supported this hypothesis as teachers used more timing reminders but not more fear appeals. Evidence from the United States showed that teachers use fear appeals and timing reminders more frequently in school districts where student test outcomes are used to inform annual job evaluations and salary increments (von der Embse et al. 2017). These results also build on the evidence base for how teacher instructional behaviours are impacted by perceived accountability pressure (e.g., Berliner 2011; Nichols and 
Valenzuela 2013). Educational systems where teacher accountability is based on student test performance, incentivize teachers to focus on tested outcomes.

We hypothesised that higher teacher self-efficacy, particularly self-efficacy in student engagement, would be related to lower use of consequence and timing reminders. That is, teachers are more inclined to use consequence reminders when they perceive students are not engaged (Putwain et al. 2017b) and efficacious teachers believe they can effectively engage their students. Our findings supported $H 2$. Teachers with high self-efficacy, for engaging students in learning, reported using less frequent fear appeals and timing reminders. Teachers with higher self-efficacy may have a greater range of tactics to engage students in their instructional and pedagogical repertoire and feel less need to modify classroom behaviours to motivate or engage students.

The perceived importance of tested outcomes was examined in relation to its relevance for teacher professional identity (Beauchamp and Thomas 2009; Gee 2000). We hypothesised that teachers who attached greater importance to test outcomes for their professional identity would report using fear appeals and timing reminders more frequently. Results supported $\mathrm{H3}$ and tally with those from the United States where von der Embse et al. (2017) also showed that higher perceived value of tested outcomes also resulted in more frequent use of fear appeals and timing reminders. Such teachers may be more likely to employ behaviours that they believe will result in higher student performance on tests and examinations, such as timing and consequence reminders. Several studies (e.g., Connor 2001, 2003; Hall et al. 2004; Putwain et al. 2012) have highlighted how school classrooms can be saturated with a focus on forthcoming examinations as a result of teacher examination-focused language in conjunction with classroom activities such as test preparation and practice.

Fear appeals and timing reminders were conceptualised as a tactic designed to encourage student motivation and engagement in their test preparation. Accordingly, we hypothesised that teachers would be less likely to use fear appeals and timing reminders if students responded with a threat appraisal, characterised by worry and anxiety. Our results did not support $H 4$. In fact, the opposite was shown and teachers were more likely to use fear appeals and timing reminders if they believed students would appraise them as threatening. This is a curious finding and not in keeping with results from Putwain and Roberts (2012). One possibility, drawn from the health promotion literature, is that in order to be effective in motivating someone to avoid a negative outcome, fear appeals must first be interpreted as threatening (Maloney et al. 2011; Popova 2012). Persons high in self-efficacy would then show adaptive emotions, cognitions, and behaviours, and persons low in self-efficacy would show the opposite. It is possible that teachers hold a lay belief similar to that proposed in the literature; in order to be motivated, students need to understand the consequences of failure. However, this interpretation remains speculatory and more research is required to understand this link further. 


\subsection{Limitations and suggestions for future research}

As noted within the procedural section, it was necessary for ethical reasons to separate the portion of the survey that included demographics from the portion of the survey that included the substantive constructs. This, unfortunately meant that it was not possible to control for teacher demographic variables in the analyses (e.g., age, gender, number of years teaching, and so on) or examine differences of theoretical interest (e.g., between primary and secondary school teachers, or schools in areas in differing levels of deprivation). As data were collected using a cross-sectional design they do not permit inferences about the direction of causality. Although, theoretically speaking, it would not be plausible for the use of fear appeals and timing reminders to influence perceived school accountability policy, the direction of causality could be bidirectional for the other relations observed. For example, teachers who used fear appeals and timing reminders more frequently might find their students less engaged and subsequently experience lower self-efficacy in their ability to engage students. Finally, the measurement of fear appeals and consequence reminders was focused on frequency and it is not known how the content of fear appeals related to consequences, may differ between teachers, subjects or different forms of assessment (e.g., informal in-class tests compared to high-stakes tests).

Despite these limitations, the findings reported here, do present a useful step towards more complex forms of analysis. Future studies should consider using two or three waves of data collection. This would enable an analysis of the directionality of relationships. Although the extensive demographic questions used in this study enable a full description of the sample characteristics, future studies may wish to consider using fewer demographic questions. This might enable the collection of demographic variables alongside substantive variables in an ethically defensible fashion. Common method variance (i.e., all measures completed by single individual) may present a limitation due to the survey design. Future research should collect student-level data that may corroborate teacher report on fear appeals and timing reminder use, and school accountability practices. Finally, observational studies may be useful in furthering contextual understanding of the content of fear appeals and timing reminders in different teachers, subjects, forms of assessment, and also different schools (e.g., those under higher or lower accountability pressures).

\subsection{Implications for policy and practice}

In light of the continued critique of the accountability by high-stakes testing agenda, and related concerns about neo-liberal educational policy more generally, there has been a renewed debate over the purpose of education (Ball 2012; Connell 2013). Specifically, educationalists have posed the question over whether education has become overly focused on passing tests and examinations (Hursh 2007), what Hutchings (2015) refers to as 'factory farm' education. The findings presented in this study contribute to the evidence base for this debate. Fear appeals and timing reminders are instructional practices that, intentionally or otherwise, raise the profile 
of high-stakes tests and their consequences in the minds of students. Since, teachers are more likely to use such behaviours when they perceive more accountability pressures, teachers can be likened to a conduit (see Reeve 2009); accountability pressures passing through teachers to students. Although the impact of fear appeals and timing reminders on student outcomes were not examined directly in this study, other findings have shown that these practices can result in educational gains or losses, depending on how they are interpreted by individual students (e.g., Putwain et al. 2017a). Teachers using such reminders to groups of students should bear this in mind. For some students they will be beneficial, but not for others.

\section{Conclusion}

This study set out to examine how the use of fear appeals and timing reminders, used prior to tests and examinations were related to pressure from above, below, and within. Fear appeals and frequency reminders were used more frequently when teachers reported lower efficacy in their capacity to engage students in learning, when the tested outcome was perceived to be important, and when teachers believed students would interpret messages as threatening. Timing reminders, but not fear appeals, were used more frequently when perceived accountability pressures were greater. These findings highlight the processes that may lead teachers to engage in certain classroom approaches prior to high-stakes examinations. From the sample analysed in this study, reasons why teachers teachers used fear appeals and timing reminders included pressure from within (self-efficacy and perceived test importance), pressure from above above (perceived accountability pressure) and pressure from below (beliefs about students' affective responses to exam messages). Given the widespread use of and importance placed upon high-stakes tests, researchers and practitioners should continue to examine the instructional context (e.g., environmental stressors, consequence and timing reminders; von der Embse and Putwain 2015) to promote student academic outcomes.

\section{Compliance with ethical standards}

Conflicts of interest The authors have no conflicts of interest to declare.

Open Access This article is distributed under the terms of the Creative Commons Attribution 4.0 International License (http://creativecommons.org/licenses/by/4.0/), which permits unrestricted use, distribution, and reproduction in any medium, provided you give appropriate credit to the original author(s) and the source, provide a link to the Creative Commons license, and indicate if changes were made.

\section{References}

Banks, J., \& Smyth, E. (2015). 'Your whole life depends on it': Academic stress and high-stakes testing in Ireland. Journal of Youth Studies, 18, 598-616. https://doi.org/10.1080/13676261.2014.992317. 
Beauchamp, C., \& Thomas, L. (2009). Understanding teacher identity: An overview of issues in the literature and implications for teacher education. Cambridge Journal of Education, 39, 175-189. https ://doi.org/10.1080/03057640902902252.

Berliner, D. (2011). Rational responses to high stakes testing: The case of curriculum narrowing and the harm that follows. Cambridge Journal of Education, 41, 287-302. https://doi.org/10.1080/03057 64X.2011.607151.

Boekaerts, M., \& Corno, L. (2005). Self-regulation in the classroom: A perspective on assessment and intervention. Applied Psychology, 54, 199-231. https://doi.org/10.1111/j.1464-0597.2005.00205.x.

Brady, L. (2011). Teacher values and relationship: Factors in values education. Australian Journal of Teacher Education, 36, 56-66. https://doi.org/10.14221/ajte.2011v36n2.5.

Cleary, T. J., \& Zimmerman, B. J. (2012). A cyclical self-regulatory account of student engagement: Theoretical foundations and applications. In S. L. Christenson, A. L. Reschley, \& C. Wylie (Eds.), Handbook of research on student engagement (pp. 237-257). London: Springer. https://doi. org/10.1007/978-1-4614-2018-7_11.

Connor, M. J. (2001). Pupil stress and standard assessment tests (SATS). Emotional and Behavioural Difficulties, 6, 103-111. https://doi.org/10.1080/13632750100507660.

Connor, M. J. (2003). Pupil stress and standard assessment tests (SATS): An update. Emotional and Behavioural Difficulties, 8, 101-107. https://doi.org/10.1080/13632750300507010.

Department for Education. (2016). School teachers' pay and conditions document 2016 and guidance on school teachers' pay and conditions. London: HMSO.

Gee, J. P. (2000). Identity as an analytic lens for research in education. Review of Research in Education, 25, 99-125. https://doi.org/10.3102/0091732X025001099.

Graham, J. W. (2012). Missing data: Analysis and design. New York: Springer.

Hall, K., Collins, J., Benjamin, S., Nind, M., \& Sheehy, K. (2004). SATurated models of pupildom: Assessment and inclusion/exclusion. British Educational Research Journal, 30, 801-817. https:// doi.org/10.1080/0141192042000279512.

Heene, M., Hilbert, S., Draxler, C., Ziegler, M., \& Bühner, M. (2011). Masking misfit in confirmatory factor analysis by increasing unique variances: A cautionary note on the usefulness of cutoff values of fit indices. Psychological Methods, 16, 319-336. https://doi.org/10.1037/a0024917.

Hu, L., \& Bentler, P. M. (1999). Cutoff criteria for fit indexes in covariance structure analysis: Conventional criteria versus new alternatives. Structural Equation Modeling: A Multidisciplinary Journal, 6, 1-55. https://doi.org/10.1080/10705519909540118.

Keith, T. Z. (2006). Multiple regression and beyond. Boston, MA: Pearson Education.

Kitsantas, A., \& Cleary, T. J. (2016). The development of self-regulated learning during secondary school years: A social cognitive instructional perspective. In K. R. Wentzel \& D. B. Miele (Eds.), Handbook of motivation at school (pp. 169-187). Oxon: Routledge.

Klassen, R. M., Bong, M., Usher, E. L., Chong, W. H., Huan, V. S., Wong, I. Y., et al. (2009). Exploring the validity of a teachers' self-efficacy scale in five countries. Contemporary Educational Psychology, 34, 67-76. https://doi.org/10.1016/j.cedpsych.2008.08.001.

Klassen, R. M., \& Chiu, M. M. (2010). Effects on teachers' self-efficacy and job satisfaction: Teacher gender, years of experience, and job stress. Journal of Educational Psychology, 102, 741-756. https ://doi.org/10.1037/a0019237.

Klassen, R. M., \& Chiu, M. M. (2011). The occupational commitment and intention to quit of practicing and pre-service teachers: Influence of self-efficacy, job stress, and teaching context. Contemporary Educational Psychology, 36, 114-129. https://doi.org/10.1016/j.cedpsych.2011.01.002.

Klassen, R. M., \& Tze, V. M. (2014). Teachers' self-efficacy, personality, and teaching effectiveness: A meta-analysis. Educational Research Review, 12, 59-76. https://doi.org/10.1016/j.edure v.2014.06.001.

Klassen, R. M., Tze, V. M., Betts, S. M., \& Gordon, K. A. (2011). Teacher efficacy research 1998-2009: Signs of progress or unfulfilled promise? Educational Psychology Review, 23, 21-43. https://doi. org/10.1007/s10648-010-9141-8.

Lance, C. E., Butts, M. M., \& Michels, L. C. (2006). The sources of four commonly reported cutoff criteria what did they really say? Organizational Research Methods, 9, 202-220. https://doi. org/10.1177/1094428105284919.

Maloney, E. K., Lapinksi, M. K., \& Witte, K. (2011). Fear appeals and persuasion: A review and update of the extended parallel process model. Social and Personality Psychology Compass, 5, 206-219. https://doi.org/10.1111/j.1751-9004.2011.00341.x. 
Metzger, S. A., \& Wu, M. J. (2008). Commercial teacher selection instruments: The validity of selecting teachers through beliefs, attitudes, and values. Review of Educational Research, 78, 921-940. https:// doi.org/10.3102/0034654308323035.

Muthén, L. K., \& Muthén, B. O. (2012). Mplus user's guide (7th ed.). Los Angeles, CA: Muthén \& Muthén.

Nichols, S. L., \& Valenzuela, A. (2013). Education policy and youth: Effects of policy on practice. Theory Into Practice, 52, 152-159. https://doi.org/10.1080/00405841.2013.804306.

OECD. (2013). Teachers for the 21st Century: Using evaluation to improve teaching. Paris: OECD Publishing.

Pelletier, L. G., Seguin-Levesque, C., \& Legault, L. (2002). Pressure from above and pressure from below as determinants of teachers' motivation and teaching behaviors. Journal of Educational Psychology, 94, 186-196. https://doi.org/10.1037/0022-0663.94.1.186.

Perry, N. E., Hutchinson, L., \& Thauberger, C. (2008). Talking about teaching self-regulated learning: Scaffolding student teachers' development and use of practices that promote self-regulated learning. International Journal of Educational Research, 47, 97-108. https://doi.org/10.1016/j.ijer.2007.11.010.

Perryman, J. (2006). Panoptic performativity and school inspection regimes: Disciplinary mechanisms and life under special measures. Journal of Education Policy, 21, 147-161. https://doi.org/10.1080/02680 930500500138

Perryman, J., Ball, S., Maguire, M., \& Braun, A. (2011). Life in the pressure cooker-School league tables and English and mathematics teachers' responses to accountability in a results-driven era. British Journal of Educational Studies, 59, 179-195. https://doi.org/10.1080/00071005.2011.578568.

Peters, E. E., \& Kitsantas, A. (2010). Self-regulation of student epistemic thinking in science: The role of metacognitive prompts. Educational Psychology, 30, 27-52. https://doi.org/10.1080/014434109033532 94.

Popova, L. (2012). The extended parallel process model: Illuminating the gaps in research. Health Education \& Behavior, 39, 455-473. https://doi.org/10.1177/1090198111418108.

Putwain, D. W., \& Best, N. (2011). Fear appeals in the primary classroom: Effects on test anxiety and test grade. Learning and Individual Differences, 21, 580-584. https://doi.org/10.1016/j.lindif.2011.07.007.

Putwain, D. W., \& Best, N. (2012). Do highly test anxious pupils respond differentially to fear appeals made prior to a test? Research in Education, 88, 1-10. https://doi.org/10.7227/RIE.88.1.1.

Putwain, D. W., Connors, E., Woods, K. A., \& Nicholson, L. J. (2012). Stress and anxiety surrounding the key stage 2 standard assessment tests in English schoolchildren. Pastoral Care in Education, 30, 189302. https://doi.org/10.1080/02643944.2012.688063.

Putwain, D. W., \& Remedios, R. (2014). Fear appeals used prior to a high-stakes examination: What makes them threatening? Learning and Individual Differences, 36, 145-151. https://doi.org/10.1016/j.lindi f.2014.10.018.

Putwain, D. W., Remedios, R., \& Symes, W. (2016a). The appraisal of fear appeals as threatening or challenging: Frequency of use, academic self-efficacy and subjective value. Educational Psychology, 36, 1677-1697. https://doi.org/10.1080/01443410.2014.963028.

Putwain, D. W., \& Roberts, C. M. (2009). The development and validation of the Teachers Use of Fear Appeals Questionnaire. British Journal of Educational Psychology, 79, 643-661. https://doi. org/10.1348/000709909X426130.

Putwain, D. W., \& Roberts, C. M. (2012). Fear and efficacy appeals in the classroom: The secondary teachers' perspective. Educational Psychology, 32, 355-372. https://doi.org/10.1080/01443410.2012.65984 5 .

Putwain, D. W., \& Symes, W. (2011a). Teachers' use of fear appeals in the mathematics classroom: Worrying or motivating students? British Journal of Educational Psychology, 81, 456-474. https://doi. org/10.1348/2044-8279.002005.

Putwain, D. W., \& Symes, W. (2011b). Classroom fear appeals and examination performance: Facilitating or debilitating outcomes? Learning and Individual Differences, 21, 227-232. https://doi.org/10.1016/j. lindif.2010.11.022.

Putwain, D. W., \& Symes, W. (2014). Subjective value and academic self-efficacy: The appraisal of fear appeals used prior to a high-stakes test as threatening or challenging. Social Psychology of Education, 17, 229-248. https://doi.org/10.1007/s11218-014-9249-7.

Putwain, D. W., \& Symes, W. (2016). The appraisal of value-promoting messages made prior to a highstakes mathematics examination: The interaction of message-focus and student characteristics. Social Psychology of Education, 19, 325-343. https://doi.org/10.1007/s11218-016-9337-y. 
Putwain, D. W., Symes, W., \& Wilkinson, H. M. (2017a). Fear appeals, engagement, and examination performance: The role of challenge and threat appraisals. British Journal of Educational Psychology, 87, 16-31. https://doi.org/10.1111/bjep.12132.

Putwain, D.W., Nakhla, G., Liversidge, A., Nicholson, L.J., Porter, B., \& Reece, M. (2017b). Teachers use of fear appeals prior to a high-stakes examination: Is frequency linked to perceived student engagement and how do students respond? Teaching and Teacher Education, 61, 73-83. https://doi. org/10.1016/j.tate.2016.10.003

Putwain, D. W., Symes, W., \& McCaldin, T. (2017c). Teacher use of loss-focused, utility value messages, prior to high-stakes examinations, and their appraisal by students. Journal of Psychoeducational Assessment. https://doi.org/10.1177/0734282917724905.

Reeve, J. (2009). Why teachers adopt a controlling motivating style toward students and how they can become more autonomy supportive. Educational Psychologist, 44, 159-175. https://doi.org/10.1080/00461 520903028990.

Roberts, N. \& Abreu, L. (2016). School inspections in England: Ofsted (Briefing Paper 07091). London: House of Commons Library. Retrieved from: http://researchbriefings.files.parliament.uk/documents/ SN07091/SN07091.pdf.

Schiefele, U., \& Schaffner, E. (2015). Teacher interests, mastery goals, and self-efficacy as predictors of instructional practices and student motivation. Contemporary Educational Psychology, 42, 159-171. https://doi.org/10.1016/j.cedpsych.2015.06.005.

Skaalvik, E. M., \& Skaalvik, S. (2007). Dimensions of teacher self-efficacy and relations with strain factors, perceived collective teacher efficacy, and teacher burnout. Journal of Educational Psychology, 99, 611-625. https://doi.org/10.1037/0022-0663.99.3.611.

Symes, W., \& Putwain, D. W. (2016). The role of attainment value, academic self-efficacy and message frame in the appraisal of value-promoting messages. British Journal of Educational Psychology, 86, 446-460. https://doi.org/10.1111/bjep.12117.

Tschannen-Moran, M., \& Woolkfolk Hoy, A. (2001). Teacher efficacy: Capturing an elusive construct. Teaching and Teacher Education, 17, 783-805. https://doi.org/10.1016/S0742-051X(01)00036-1.

Tschannen-Moran, M., \& Woolkfolk Hoy, A. (2007). The differential antecedents of self-efficacy beliefs of novice and experienced teachers. Teaching and Teacher Education, 23, 944-956. https://doi. org/10.1016/j.tate.2006.05.003.

Tschannen-Moran, M., Woolfolk Hoy, A., \& Hoy, W. K. (1998). Teacher efficacy: Its meaning and measure. Review of Educational Research, 68, 202-248. https://doi.org/10.3102/00346543068002202.

von der Embse, N. P., \& Putwain, D. W. (2015). Examining the context of instruction to facilitate student success. School Psychology International, 36, 552-558. https://doi.org/10.1177/0143034315612144.

von der Embse, N. P., Schoemann, A. M., Kilgus, S. P., Wicoff, M., \& Bowler, M. (2017). The influence of test-based accountability policies on teacher stress and instructional practices: A moderated mediation model. Educational Psychology, 37, 312-331. https://doi.org/10.1080/01443410.2016.1183766.

von der Embse, N. P., Shultz, B. K., \& Draughn, J. D. (2015). Readying student to test: The influence of fear and efficacy appeals on anxiety and test performance. School Psychology International, 36, 620-637. https://doi.org/10.1177/0143034315609094.

Zimmerman, B. J. (2000). Attainment of self-regulation: A sociocognitive perspective. In M. Boekaerts, P. Pintrich, \& M. Zeidner (Eds.), Handbook of self-regulation (pp. 13-39). Cambridge: Cambridge University Press.

David W. Putwain is a Professor of Education and Early Childhood, and Director of the Centre for Educational Research, in the School of Education at Liverpool John Moores University. His research interests include motivation, emotions, engagement, and the role of the school and classroom environment.

Nathaniel P. von der Embse is an Assistant Professor of School Psychology in the College of Education at the University of South Florida. His research interests include universal screening for behavioural and mental health, test anxiety and teacher stress, and training educators in population-based mental health services. 